\title{
A trial of expectant management in incomplete miscarriage
}

\author{
P S Wijesinghe ${ }^{1}$, G S Padumadasa', T S Palihawadana', F S Marleen ${ }^{2}$ \\ (Index words: incomplete miscarriage, expectant management, evacuation of retained products of conception)
}

\begin{abstract}
Introduction Incomplete miscarriage is often treated with surgical evacuation in Sri Lanka. Expectant management, which is an alternative treatment, was assessed for efficacy and safety in a local setting.

Methods Randomised clinical trial of two treatment groups of expectant and surgical management with 71 and 69 participants, respectively, was done at the University Gynaecology Unit of the Colombo North Teaching Hospital, Ragama, from December 2007 to July 2009. Women with incomplete miscarriage at a period of amenorrhoea of $<14$ weeks and retained products of conception of $<50 \mathrm{~mm}$ were included. Expectant management involved in-ward treatment till resolution of heavy bleeding and pain and follow up for two weeks. In surgical treatment, evacuation was undertaken and the patient sent home from hospital after bleeding settled with follow up. The maximum anteroposterior diameter of the endometrial cavity was measured with transvaginal ultrasonography and a diameter $<15 \mathrm{~mm}$ was considered as complete miscarriage.
\end{abstract}

Results Expectant management had a treatment success of $90.1 \%$ at one week and $94.4 \%$ at two weeks. For surgical treatment this was $95.7 \%$. Infection was noted in one subject from the surgical group and none in the expectant group. Fall in the haemoglobin concentration in the two groups was clinically not significant. The expectantly managed group had a shorter hospital stay than the surgically managed group (1.58 vs 2.57 days, $p=0.008$ ).

Conclusions Expectant management is an effective and safe alternative to surgical evacuation in management of incomplete miscarriage in the local setting. It relieves the burden on the healthcare provider by shortening the hospital stay and avoiding the need for evacuation of retained products of conception under anaesthesia.

Ceylon Medical Journal 2011; 56: 10-13

\section{Introduction}

Spontaneous expulsion of a fetus or an embryo weighing $500 \mathrm{~g}$ or less at a period of amenorrhoea deemed incompatible with viability occurs in $10-20 \%$ of clinical pregnancies [1]. Incomplete miscarriage is diagnosed in the presence of uterine bleeding and passage of products of conception with abdominal pain and a dilated cervical os on clinical examination. Ultrasonography is used to confirm the diagnosis by measuring the amount of retained products of conception (RPOC) in the maximum anteroposterior diameter (AP diameter) of the endometrial cavity [2].

Surgical evacuation has been the standard treatment for incomplete miscarriage over the years. This was based on the assumption that spontaneous expulsion would be incomplete and thereby increase the risk of infection and haemorrhage. In the recent past up to $88 \%$ of women with miscarriage underwent surgical evacuation [3].

Although a minor procedure, surgical evacuation is associated with rare but serious morbidity. Complications include haemorrhage, tearing or laceration of the cervix, perforation of the uterus, pelvic infection and very rarely bowel and bladder damage, broad ligament haematoma, secondary infertility, Asherman syndrome as well as anaesthetic complications [4]. The incidence of serious morbidity following surgical evacuation has been estimated at $2.1 \%$ while the mortality is around 0.5 per 100,000 [5]. Medical and expectant management are two alternative treatment modalities that are in clinical practice and have shown to be effective and safe $[6,7,8]$. Expectant management is deemed suitable when the amount of RPOC is between $15-50 \mathrm{~mm}$ in the AP diameter with no haemodynamic instability $[9,10,11]$.

Previous studies comparing expectant management with surgical or medical management have shown a wide variation in efficacy and this is estimated to be in the range of $25-100 \%$ [12-18]. Diversity of study populations, inclusion of different types of miscarriages of varying periods of amenorrhoea with different follow up protocols are responsible for this wide range of efficacy. Although concerns have been raised about the infective risk, published data suggest a reduction in pelvic infection and adverse effects on future fertility with expectant management compared to other treatment modalities [19].

In the absence of early pregnancy assessment units, miscarriage is the commonest indication for emergency admissions to gynaecological units in Sri Lanka and contributes substantially to the health expenditure in relation to manpower, operating theatre time and hospital stay [20]. Published data suggest that expectant

${ }^{1}$ Department of Obstetrics and Gynaecology, Faculty of Medicine, University of Kelaniya, Ragama and ${ }^{2}$ University Obstetrics and Gynaecology Unit, Colombo North Teaching Hospital, Ragama, Sri Lanka.

Correspondence: PSW, e-mail <prasanthaw@gmail.com>. Received 28 June and revised version accepted October 2010. Competing interests: none declared. 
management is less costly to the healthcare provider in comparison to surgical management [21]. Ready accessibility to a healthcare facility may vary among our patients. Furthermore the safety of outpatient management in our context is unclear. We have compared the efficacy and safety of expectant and surgical management of incomplete miscarriage in a Sri Lankan clinical setting. This is the first such study conducted in the country to our knowledge.

\section{Methods}

The study was carried out as a randomised clinical trial at the University Gynaecology Unit, North Colombo Teaching Hospital, Ragama from December 2007 to July 2009. The study was registered with the Sri Lanka Clinical Trials Registry of the Sri Lanka Medical Association (SLCTR/2008/012) and was approved by the Ethical Review Committee of the Faculty of Medicine, Ragama.

The aim of the study was to compare the efficacy and safety of expectant versus surgical management of incomplete miscarriage presenting before 14 weeks of amenorrhoea with ultrasound evidence of RPOC of 15-50 $\mathrm{mm}$ in the AP diameter. Women who presented with profuse vaginal bleeding with pain, fever, haemodynamic instability or evidence of sepsis necessitating immediate surgical evacuation were excluded from the study. Patients with incomplete miscarriage following attempted termination of pregnancy were also excluded from the study as the risk of infection made them unsuitable to be managed expectantly. A total of 140 women were recruited. Following informed written consent, the participants were allocated to the two groups using computer generated random numbers: the expectant group and the surgical group.
Women allocated to surgical management underwent surgical evacuation of retained products of conception (ERPC) within 24 hours of the ultrasound evaluation. Prior to discharge from the hospital, a repeat ultrasound scan was carried out to confirm adequate evacuation. If the evacuation was considered inadequate a repeat evacuation was offered. A follow up evaluation was done after two weeks. Those in the expectant group were sent home once bleeding settled and reviewed weekly until AP diameter was $<15 \mathrm{~mm}$ up to a period of two weeks. At the end of the two weeks if there were RPOC with an AP diameter of $>15 \mathrm{~mm}$, they were offered surgical evacuation. At each evaluation the women were assessed for complications. Apart from the above, the management was similar in the two groups and was in accordance with the routine clinical practice of the unit. In both groups a full blood count (FBC) was done on admission and at the follow up visit. Prophylactic antibiotics were not given. All women had access to emergency hospital admission at all times during the study in case of unexpected symptoms. The treatment success rate, incidence of complications and the hospital stay were compared between the two treatment modalities.

Statistical analysis was done using SPSS v11 statistical software programme. Chi square test was used to compare success rates and complications between the two groups. Student t test was used to compare the drop in haemoglobin level and duration of hospital stay.

\section{Results}

Of the 140 participants recruited for the study 71 were allocated to the expectant group and 69 to the surgical group. There was no statistically significant difference in socio-demographic and basic clinical characteristics between the two groups (Table 1).

Table1. Socio-demographic and clinical characteristics of the two study groups $(n=140)$

\begin{tabular}{|c|c|c|c|c|c|}
\hline \multirow[b]{2}{*}{ Mean (SD) Age in years } & \multicolumn{2}{|c|}{$\begin{array}{l}\text { Expectant } \\
(\mathrm{n}=71)\end{array}$} & \multicolumn{2}{|c|}{$\begin{array}{c}\text { Surgical } \\
(\mathrm{n}=69)\end{array}$} & \multirow{2}{*}{$\begin{array}{c}p \text { value } \\
0.506\end{array}$} \\
\hline & 29.19 & $(5.67)$ & 28.51 & (6.39) & \\
\hline \multicolumn{6}{|l|}{ Parity } \\
\hline 1 & 33 & $(46 \%)$ & 24 & $(35 \%)$ & 0.239 \\
\hline 2 & 19 & $(27 \%)$ & 17 & $(25 \%)$ & \\
\hline 3 & 10 & $(14 \%)$ & 19 & $(28 \%)$ & \\
\hline 4 & 6 & $(9 \%)$ & 8 & $(11 \%)$ & \\
\hline$>4$ & 3 & $(4 \%)$ & 1 & $(1 \%)$ & \\
\hline Mean (SD) POA in days & 73.13 & (13.4) & 72.25 & $(15.5)$ & 0.720 \\
\hline Mean (SD) Max AP diameter in mm & 18.5 & (4.6) & 19.0 & $(6.2)$ & 0.588 \\
\hline Mean (SD) $\mathrm{Hb}$ at admission (g/dl) & 11.95 & $(1.2)$ & 11.77 & $(1.5)$ & 0.180 \\
\hline
\end{tabular}

Max AP = Maximum antero-posterior measurement of retained products of conception on transvaginal ultrasonography $\mathrm{Hb}=$ Haemoglobin concentration 
Table 2. The treatment outcome in the two study groups $(n=140)$

\begin{tabular}{lccc}
\hline & $\begin{array}{c}\text { Expectant } \\
(\mathrm{n}=71)\end{array}$ & $\begin{array}{c}\text { Surgical } \\
(\mathrm{n}=69)\end{array}$ & p value \\
\hline Treatment success after 2 weeks No (\%) & $67(94.4)$ & $66(95.7)$ & 0.516 \\
Need for unscheduled ERPC No (\%) & $4(5.6)$ & $3(4.3)$ & 0.523 \\
Complications & 0 & 1 & 0.493 \\
Sepsis & 0 & 0 & \\
Uterine perforation & 0 & 0 & 0.0003 \\
Need for blood transfusion & $0.72(0.2)$ & $0.91(0.12)$ & 0.008 \\
Hb drop; mean (SD) (g/dL) & $1.58(0.66)$ & $2.57(0.82)$ & \\
Hospital stay (days); mean (SD) & & & \\
\hline
\end{tabular}

ERPC = Evacuation of retained products of conception

$\mathrm{Hb}$ drop $=$ Difference of $\mathrm{Hb}$ between recruitment and after two weeks

In the expectant group, $64(90.1 \%)$ women had a complete miscarriage at the end of one week, while it was complete in 67 (94.4\%) women at the end of two weeks. Unscheduled surgical evacuation was carried out in the remaining four patients. In the surgical group, $66(95.7 \%)$ women had a complete evacuation after the initial surgical evacuation. Unscheduled repeat surgical evacuation was necessary in the remaining three patients due to incomplete evacuation at the initial procedure and persistent bleeding.

Genital sepsis was not seen in any of the patients in the expectant group while one woman who underwent a repeat surgical evacuation in the surgical group developed clinically evident endometritis. There was no heavy intraoperative blood loss, uterine or cervical damage, need for blood transfusion or anaesthetic complications among any of the participants. The mean (SD) $\mathrm{Hb}$ concentrations after one week from recruitment were $11.23(1.4) \mathrm{g} / \mathrm{dl}$ and 10.86 (1.2) $\mathrm{g} / \mathrm{dl}$ in the expectant and surgical groups respectively. There was a statistically significant mean drop in $\mathrm{Hb}$ concentration $(0.72 \mathrm{~g} / \mathrm{dl}$ vs. $0.91 \mathrm{~g} / \mathrm{dl}, p=0.0003)$. The mean (SD) duration of hospital stay for the expectantly and surgically managed patients were $1.58(0.66)$ days and 2.57 $(0.82)$ days $(p=0.008)$ respectively. Details of the treatment outcome of the two groups are shown in Table 2.

\section{Discussion}

In Sri Lanka surgical evacuation is commonly used in the management of incomplete miscarriage incurring a heavy burden on healthcare resources. Alternate methods such as expectant and medical management are commonly used in more developed settings. Local data are important in counselling the patients prior to offering such treatment modalities.

The patient population of this study comprised of those with incomplete miscarriage presenting before 14 weeks of amenorrhoea and with minimal RPOC (mean (SD) AP diameter of 18.59 (4.6) $\mathrm{mm}$ and 19.0 (6.2) $\mathrm{mm}$ in the two groups, $p=0.588$ ). It is a common presentation in the local setting as many patients tend to present late having expelled much of the products of conception and thus making them suitable for expectant management.

This study demonstrates that expectant management up to a period of two weeks obviates surgical evacuation in nearly $95 \%$ of patients. It does not increase the risk of infection or reduce the haemoglobin concentration to clinically significant levels or increase the incidence of unscheduled surgical evacuations. These findings were similar to previous studies done in other parts of the world $[22,23]$. The patients who had expectant management had a shorter hospital stay compared to those who were managed by surgical evacuation.

It should be highlighted that a minority of patients who are managed expectantly may experience heavy bleeding or pain which may require urgent attention and therefore access to a healthcare facility should be made available at all times to these patients. Patient acceptance of expectant management, loss of income and work, and effects on the quality of life are some other pertinent areas that need attention.

\section{Conclusion}

Expectant management is an effective and safe alternative to surgical evacuation for incomplete miscarriage before 14 weeks of amenorrhoea confirmed by ultrasound with retained products of $15-50 \mathrm{~mm}$ in the maximum antero-posterior diameter of the endometrial cavity. It reduces the burden on the healthcare provider by shortening the hospital stay and obviating the need for surgical evacuation of retained products of conception among these women. 


\section{Acknowledgements}

We acknowledge the financial support given by the National Science Foundation of Sri Lanka through grant number RG/2007/HS/07.

\section{References}

1. Alberman E. Spontaneous abortion: epidemiology. In: Stabile S, Grudzinskas G, Chard T, editors. Spontaneous abortion: diagnosis and treatment. London: Springer-Verlag; 1992: 9-20.

2. Rulin MC, Bornstein SG, Campbell JD. The reliability of ultrasonography in the management of spontaneous abortion, clinically thought to be complete: a prospective study. American Journal of Obstetrics and Gynecology 1993; 168: $12-5$.

3. Hemminki E. Treatment of miscarriage: current practice and rationale. Obstetrics and Gynecology 1998; 91: 247-53.

4. Ratnam SS, Prasad RNV. Medical management of abnormal pregnancy. Bailliere's Clinical Obstetrics and Gynaecology 1990; 4: 361-74.

5. Lawson HW, Frye A, Atrash HK, Smith JC, Shulman HB, Ramick M. Abortion mortality, United States, 1972 through 1987. American Journal of Obstetrics and Gynecology 1994; 171: 1365-72.

6. Royal College of Obstetricians and Gynaecologists. Management of early pregnancy loss. RCOG Green top Guideline 25. 2006.

7. Jurkovic D, Ross JA, Nicolaides KH. Expectant management of miscarriage. British Journal of Obstetrics and Gynaecology 1998; 105: 670-1.

8. Ballagh SA, Harris HA, Demasio K. Is curettage needed for an uncomplicated incomplete abortion? American Journal of Obstetrics and Gynecology 1998; 179: 1279-82.

9. Sairam S, Khare M, Michailididis G, Thilaganathan B. The role of ultrasound in the expectant management of early pregnancy loss. Ultrasound in Obstetrics and Gynecology 2001; 17: 506-9.

10. Luise C, Jermy K, May C, Costello G, Collins WP, Bourne TH. Outcome of expectant management of spontaneous first trimester miscarriage: observational study. British Medical Journal 2002; 324: 873-5.

11. Sotiriadis A, Makrydimas G, Papatheodorou S, Ioannidis JP. Expectant, medical or surgical management of firsttrimester miscarriage: a meta-analysis. Obstetrics and Gynecology 2005; 105: 1104-13.
12. Hurd WW, Whitfield RR, Randolph JF Jr, Kercher ML. Expectant management versus elective curettage for the treatment of spontaneous abortion. Fertility Sterility 1997; 68: $601-06$.

13. Nielsen S, Hahlin M. Expectant management of first trimester spontaneous abortion. Lancet 1995; 345: 84-6.

14. Nielsen S, Hahlin M, Platz-Christensen J. Randomized trial comparing expectant with medical management for first trimester miscarriages. British Journal of Obstetrics and Gynaecology 1999; 106: 804-7.

15. Jurkovic D. Modern management of miscarriage: is there a place for non-surgical treatment? Ultrasound in Obstetrics and Gynecology 1998; 11: 161-3.

16. Chipchase J, James D. Randomised trial of expectant versus surgical management of spontaneous miscarriage. British Journal of Obstetrics and Gynaecology 1997; 104: 840-1.

17. Wieringa-de Warrd M, Vos J, Bonsel GJ, Bindels PJE, Ankum WM. Management of miscarriage: a randomised controlled trial of expectant management versus surgical evacuation. Human Reproduction 2002; 17: 2445-50.

18. Nanda K, Peloggia A, Grimes D, Lopez L, Nanda G. Expectant care versus surgical treatment for miscarriage. Cochrane Database of Systematic Reviews 2006, Issue 2. Art. No. CD003518. DOI: 10.1002-14651858.CD003518. pub2.

19. Blohm F, Hahlin M, Nielsen S, Milsom I. Fertility after a randomised trial of spontaneous abortion managed by surgical evacuation or expectant treatment. Lancet 1997; 349: 995 7.

20. Petrou S, Trinder J, Brocklehurst P, Smith L. Economic evaluation of alternative management methods of first trimester miscarriage based on the results from the MIST trial. British Journal of Obstetrics and Gynaecology 2006; 113: 879-89.

21. You JHS, Chung TKH. Expectant, medical or surgical treatment for spontaneous abortion in first trimester of pregnancy: a cost analysis. Human Reproduction 2005; 20: 2873-8.

22. Hinshaw HKS. Medical management of miscarriage. In: Grudzinskas JG, O'Brien PMS, editors. Problems in Early Pregnancy: Advances in Diagnosis and Management. London: RCOG press 1997; 284-95.

23. Trinder J, Brocklehurst P, Porter R, Read M, Vyas S, Smith L. Management of miscarriage: expectant, medical or surgical? Results of randomised controlled trial (miscarriage treatment (MIST) trial). British Medical Journal 2006; 332: $1235-40$. 